\title{
Repeated concussion among U.S. military personnel during Operation Iraqi Freedom
}

\author{
Andrew J. MacGregor, PhD, MPH; Amber L. Dougherty, MPH; ${ }^{*}$ Rosemary H. Morrison, MPH; Kimberly H. \\ Quinn, BS; Michael R. Galarneau, MS \\ Department of Medical Modeling, Simulation, and Mission Support, Naval Health Research Center, San Diego, CA
}

\begin{abstract}
Concussions are a predominant injury of the conflicts in Iraq and Afghanistan. The aims of this study were to describe repeated concussive events among U.S. military personnel injured in Operation Iraqi Freedom and examine subsequent healthcare utilization. We reviewed clinical records from the Expeditionary Medical Encounter Database to identify servicemembers with repeat concussions. We abstracted demographic and injury-specific variables, calculated time between events, and identified healthcare utilization from electronic medical databases. Overall, 113 personnel experienced more than one concussion between 2004 and 2008. A majority of these incidents were blast related. The median time between events was 40 days, with $20 \%$ experiencing a second event within 2 weeks of the first and $87 \%$ within 3 months. Time between events was not associated with severity of the second event. Greater severity of the second concussive event was associated with higher postinjury utilization of mental health and neurology services. This study is one of the first to describe repeated concussions in a combat setting. We found that repeated concussions occur within a short interval among deployed personnel, although the effects of the first event are unclear. Further research is needed to define the effect of repeated concussions on the health of combat veterans.
\end{abstract}

Key words: blast, combat, concussion, concussive injury, deployment, head injury, head trauma, military, multiple, severity, traumatic brain injury.

\section{INTRODUCTION}

Traumatic brain injury (TBI) is one of the predominant injuries of the current military conflicts in Iraq and Afghanistan, with prevalence ranging from 15 to 20 percent depending on the diagnostic criteria and patient population [1-7]. A majority of these injuries, 85 percent in one study, are mild concussions resulting from exposure to blasts [1-4,7]. Because military personnel with mild injuries are often returned to full duty status shortly after the injury-causing event, understanding the lasting effects on cognitive and physical functions, as well as the risks associated with repeat injury, is of significant importance [8].

Although research describing the effects of repeated concussions in military populations is limited, civilian literature points to several detrimental physical, cognitive, and emotional health effects of incurring multiple

\footnotetext{
Abbreviations: AIS $=$ Abbreviated Injury Scale; $\mathrm{CI}=$ confidence interval; EMED = Expeditionary Medical Encounter Database; ICD-9-CM = International Classification of Diseases, 9th Revision, Clinical Modification; ISS = Injury Severity Score; $\mathrm{LOC}=$ loss of consciousness; NHRC $=$ Naval Health Research Center; OR = odds ratio; SADR = Standard Ambulatory Data Record; TBI = traumatic brain injury.

*Address all correspondence to Amber L. Dougherty, MPH; Naval Health Research Center, 140 Sylvester Rd, San Diego, CA 92106-5122; 619-368-6853; fax: 619-5538378. Email: amber.dougherty@med.navy.mil

DOI:10.1682/JRRD.2011.01.0013
} 
concussions [9-13]. Evidence exists that some aspects of neurocognitive function do not recover as quickly in those who have experienced multiple concussions, and some studies suggest a permanent reduction in cognitive performance [14-15]. One recent study showed greater reduction in neurological activity among persons with two concussions, with reduced time between concussive events acting as an important mediator [16].

The aims of the present study were to (1) provide a descriptive analysis of repeated concussion in U.S. military personnel, (2) identify whether decreased time between events is associated with increased severity of the second event, and (3) identify predictors of postinjury utilization of mental health and neurology outpatient services following the second concussive event.

\section{METHODS}

\section{Study Design}

The present study was an analysis of servicemembers with repeated concussions that were reported in the Expeditionary Medical Encounter Database (EMED) (formerly the Navy-Marine Corps Combat Trauma Registry). The EMED is a deployment health database maintained by Naval Health Research Center (NHRC), San Diego, California, and consists of documented clinical encounters of deployed military personnel from all service branches (a more extensive description of the EMED can be found elsewhere [17]).

\section{Data Sources}

Clinical EMED records were completed by medical providers stationed at forward-deployed Navy-Marine Corps military treatment facilities that were located in Iraq to treat Operation Iraqi Freedom casualties. Unique aspects of the EMED include detailed information regarding the injury incident, which is collected at or near the point of occurrence, as well as the inclusion of persons with otherwise mild injuries who are subsequently returned to duty. Clinical records are provided to NHRC, and professional coders review the records and assign codes using the Abbreviated Injury Scale (AIS); Injury Severity Score (ISS); and International Classification of Diseases, 9th Revision, Clinical Modification (ICD-9CM) [18-20].

\section{Study Sample}

For the present study, eligible personnel were servicemembers who sustained two or more provider-diagnosed concussions during Operation Iraqi Freedom from March 2004 to April 2008. A concussion was defined by the presence of an ICD-9-CM code of 850.0 to 850.9. Severity of concussion was defined using the AIS, which is a scoring system that details the severity of each injury and is categorized into nine different body regions (i.e., head, neck, face, torso, abdomen, spine, upper limb, lower limb, and external) [18]. All personnel in the study sustained concussions corresponding to a maximum head AIS of 1 (minor injury) or 2 (moderate injury). At the time of the present study, 113 of 14,653 individuals in the EMED with combat or noncombat injury met the inclusion criteria and comprised the study sample. Overall injury severity for each servicemember was determined with the ISS, which is derived from the AIS and ranges from 0 to 75 [19]. Because of a small number of individuals with more than two concussive events $(n=6)$, analysis was restricted to the first two events.

\section{Measures}

\section{Demographic Variables}

Age, military rank, branch of service, and occupational specialty at the time of the initial concussive event were abstracted from the EMED clinical record and validated with information from the Defense Manpower Data Center, which maintains administrative records for all military personnel. Military rank was categorized as junior enlisted (E1-E3), midlevel enlisted (E4-E5), senior enlisted (E6-E9), and officer/warrant officer. Branch of service was categorized into Marine Corps, Army, and Navy. Occupation was defined as infantry or other/unknown based on indication of an infantry-related job specialty (general infantry, rifleman, mortarman, missileman, or machine gunner).

\section{Injury-Specific Variables}

Type of injury was categorized as combat, injury as a result of hostile action, or noncombat, defined as injury resulting from nonhostile action. Injury mechanism was indicated on the EMED clinical record and was categorized into "blast" or "nonblast." Loss of consciousness (LOC) information was available for 73.4 percent (83 of 113) of initial concussive events and 74.3 percent (84 of 113) of second concussive events. 


\section{Time Between Events}

Time between events was calculated by subtracting the dates of injury for the first and second concussive event for each individual. This difference in injury dates was then used to establish three cutoff points in order to explore how time between events might be associated with injury severity and healthcare utilization. As per previous literature, the first and second cutoff points explored differences between those with concussive events that occurred (1) less than or equal to 2 weeks or greater than 2 weeks apart and (2) less than or equal to 3 months or greater than 3 months apart [21]. We used a third cutoff point, median time between events, in order to apportion comparison groups equally.

\section{Severity of Second Injury}

A variable was created to indicate whether the second concussive event was more severe than the first event according to the head AIS (i.e., head AIS increased from 1 to 2$)$.

\section{Healthcare Utilization}

Because the most common symptoms after a concussion are cognitive (decreased memory, attention, and concentration), somatic (headache, fatigue, insomnia, dizziness, tinnitus, and sensitivity to noise or light), and affective (depression, irritability, and anxiety), utilization of mental health and neurology services was examined [22]. Utilization of mental health and neurology outpatient services was identified from the Standard Ambulatory Data Record (SADR) database. The SADR electronic database contains a Medical Expense and Performance Reporting System code for each outpatient visit, which indicates the type of clinic for each patient encounter.

It is standard practice for military personnel to be referred for a follow-up visit postinjury. To capture true utilization of healthcare due to continuing problems beyond the initial follow-up, we defined utilization as two or more visits to mental health (identified as psychology, psychiatry, mental health, or substance abuse) or neurology clinics within 24 months of the second concussion. Mental health and neurology utilization were examined separately. Personnel with more than two documented concussions $(n=6)$ were restricted from this analysis. Other types of healthcare utilization were examined for descriptive purposes and included primary care, general medicine/surgery, physical or occupational therapy, audiology, and other.

\section{Data Analysis}

All statistical analyses were performed using SPSS, version 17.0 (SPSS Inc; Chicago, Illinois). Comparisons between concussive events were conducted using Wilcoxon signed rank and McNemar tests for dependent samples. The association of time between events and increased severity at the second concussive event was assessed using chi-square and Fisher exact tests. Healthcare utilization was described by number of clinic visits in the first and second years following the second concussive event. Age-adjusted logistic regression analysis was used to examine the predictive effect of concussion severity and time between events on utilization of mental health and neurology outpatient services.

\section{RESULTS}

Demographic statistics for the study sample are summarized in Table 1. The study sample consisted of 113 servicemembers injured during deployment in Operation Iraqi Freedom. The median age was 21 years (range 18$39)$ and consisted primarily of Marines (92.0\%). Overall, 94.7 percent $(n=107)$ experienced two concussive events and 5.3 percent $(n=6)$ experienced three or four. At the time of the first event, the majority were in infantry positions and junior enlisted.

Table 1.

Demographic characteristics of 113 servicemembers who sustained two or more concussions during deployment in Operation Iraqi Freedom.

\begin{tabular}{lc}
\hline \multicolumn{1}{c}{ Characteristic } & Median (Range) or $\boldsymbol{n}(\%)$ \\
\hline Age (yr) & $21(18-39)$ \\
Rank & \\
Junior Enlisted & $68(60.2)$ \\
Midlevel Enlisted & $35(31.0)$ \\
Senior Enlisted & $6(5.3)$ \\
Officer/Warrant Officer & $4(3.5)$ \\
Service & \\
Marine Corps & $104(92.0)$ \\
Army & $6(5.3)$ \\
Navy & $3(2.7)$ \\
Occupation & \\
Infantry & $76(67.3)$ \\
Other/Unknown & $37(32.7)$ \\
\hline \hline
\end{tabular}


Types of concussion at the first and second event are detailed in Table 2. Of those in which presence or absence of LOC could be confirmed, a majority did not experience LOC at either the first (57 of 83, 69\%) or second (51 of $84,61 \%)$ event. Overall, 68 individuals had confirmed presence or absence of LOC for both concussive events. Of these, more than half (14 of 23) who experienced LOC at their first event also experienced confirmed LOC at their second, compared with only 29 percent (13 of 45) of personnel without LOC at their first event, although this difference was not statistically significant $($ McNemar $p$-value $=0.52$ ).

Results shown in Table 3 compare injury-specific characteristics of the first and second concussive events. For both the first and second event, over 90 percent were combat-related and caused by blast mechanisms. No statistical differences were found between the first and second event by type and mechanism of injury or maximum head AIS and ISS. Overall, 16 percent (18 of 113) had an increase in head AIS at the second concussive event.

The median time between events was 40 days (range 2-753, interquartile range 20-75), with 19 percent (22 of 113) of repeated concussive events occurring within an interval of 2 weeks and 87 percent (98 of 113) occurring within 3 months. As shown in Table 4, the time between repeated concussive events at the median, 2-week, and 3month intervals was not associated with an increase in head AIS from the first to second event.

Healthcare utilization for the 107 personnel with only two concussions is shown in Table 5. General medicine/ surgery accounted for the largest proportion of healthcare visits in the first year following repeat concussion, while primary care visits accounted for the largest proportion in the second year. Table 6 displays both unadjusted and adjusted results of the mental health and neurology utilization regression analysis. Utilization of mental health and neurology outpatient services was indicated for 17 percent $(n=18)$ and 33 percent $(n=35)$ of personnel, respectively. In age-adjusted logistic regression analysis, time between events was not associated with an increase in clinic utilization. Severity of second concussive event, however, was significantly associated with mental health (odds ratio $[\mathrm{OR}]=4.74,95 \%$ confidence interval $[\mathrm{CI}]=$ $1.52-14.75, p$-value $=0.01)$ and neurology $(\mathrm{OR}=3.41$, $95 \%$ CI $=1.32-8.75, p$-value $=0.01$ ) clinic utilization. Results did not change after including severity of first event, severity of second event, time between events, and age together in one multivariable model.

Table 2.

Distribution of first and second concussive events by type ( $n=113)$. Data reported as $n(\%)$.

\begin{tabular}{|c|c|c|c|c|}
\hline \multirow{2}{*}{$\begin{array}{l}\text { First Concussion } \\
\text { (ICD-9-CM code) }\end{array}$} & \multicolumn{4}{|c|}{ Second Concussion } \\
\hline & No LOC & LOC $\leq 30$ min & LOC, NOS & Concussion, NOS \\
\hline No LOC (850.0) & $32(56.1)$ & $12(21.1)$ & $1(1.8)$ & $12(21.1)$ \\
\hline $\mathrm{LOC} \leq 30 \min (850.11)$ & $6(33.3)$ & $10(55.6)$ & $1(5.6)$ & $1(5.6)$ \\
\hline LOC, NOS (850.5) & $3(37.5)$ & $2(25.0)$ & $1(12.5)$ & $2(25.0)$ \\
\hline Concussion, NOS (850.9) & $10(33.3)$ & $6(20.0)$ & $0(0.0)$ & $14(46.7)$ \\
\hline
\end{tabular}

Note: Percentages are calculated by row. Because of rounding, percentages may not total 100 .

ICD-9-CM = International Classification of Diseases, 9th Revision, Clinical Modification; LOC = loss of consciousness; NOS = not otherwise specified.

Table 3.

Distribution of first and second concussive events by injury-specific characteristics $(n=113)$.

\begin{tabular}{lccc}
\hline \multicolumn{1}{c}{ Characteristic } & First Concussion & Second Concussion & $p$-Value \\
\hline Combat Injury, $n(\%)$ & $107(94.7)$ & $109(96.5)$ & $0.63^{*}$ \\
Blast Mechanism, $n(\%)$ & $105(92.9)$ & $107(94.7)$ & $0.73^{*}$ \\
Severity Indicator & & & \\
ISS, Mean \pm SD & $2.5 \pm 1.6$ & $2.8 \pm 2.1$ & $0.46^{\dagger}$ \\
Head AIS, Mean \pm SD & $1.2 \pm 0.4$ & $1.3 \pm 0.4$ & $0.60^{\dagger}$ \\
Maximum Head AIS 2, $n(\%)$ & $27(23.9)$ & $30(26.6)$ & $0.60^{*}$ \\
\hline
\end{tabular}

${ }^{*}$ McNemar test.

${ }^{\dagger}$ Wilcoxon signed rank test.

AIS = Abbreviated Injury Scale, ISS = Injury Severity Score, SD = standard deviation. 
Table 4.

Effect of time between concussive events on severity of second concussion ( $n=113)$.

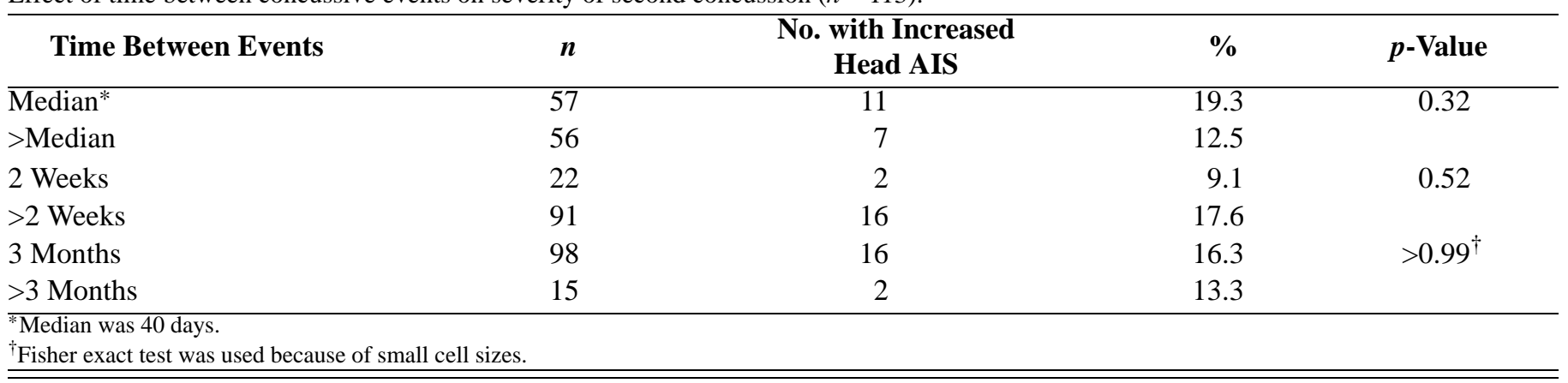

Table 5.

Healthcare utilization in 2 years following second concussive event $(n=107)$.

\begin{tabular}{|c|c|c|c|c|}
\hline Type of Clinic & \multicolumn{2}{|c|}{$\begin{array}{c}\text { 0-12 Months } \\
\text { After 2nd Concussive Event }\end{array}$} & \multicolumn{2}{|c|}{$\begin{array}{l}\text { 12-24 Months } \\
\text { After 2nd Concussive Event }\end{array}$} \\
\hline Primary Care & 334 & 14.9 & 325 & 28.3 \\
\hline Physical or Occupational Therapy & 563 & 25.2 & 160 & 13.9 \\
\hline Mental Health & 229 & 10.2 & 251 & 21.9 \\
\hline Other & 150 & 6.7 & 61 & 5.3 \\
\hline Total Visits & 2,235 & 100.0 & 1,148 & 100.0 \\
\hline
\end{tabular}

\section{DISCUSSION}

Concussions are common among U.S. military personnel serving in Iraq and Afghanistan. Though multiple studies have detailed the occurrence of combat-related TBI, the present study extends the analysis to those with repeated concussive events. A key finding was the high proportion of repeated concussions that occurred within a short period of time, as high as 20 percent within 2 weeks and 87 percent within 3 months of the first event. One previous study among professional football players found repeated concussions occurred among 4 percent and 20 percent of the sample at 2 weeks and 3 months, respectively [21]. Another study in college football players found that 9 of 12 players who had within-season concussions experienced the repeat concussion within 1 week of the initial concussion [23]. Unfortunately, neither of these studies assessed the effect of time between concussions on concussion severity or healthcare utilization.

In our analysis, healthcare utilization was not statistically associated with severity of the initial concussive event. A statistically positive association was found, however, between increased severity of the second event and mental health and neurology clinic utilization. These findings suggest that the most recent concussive event, as opposed to cumulative effects of concussions, may be more predictive of subsequent healthcare utilization. Alternatively, comparing personnel with multiple concussions to personnel with a single concussive event may be more effective in elucidating any cumulative effects and should be a focus of future research. Because a recent policy change proposed by the Chairman of the Joint Chiefs of Staff would restrict personnel to noncombat duty following their third concussion, further research is needed on the effects of repeated concussions among combat veterans. ${ }^{*}$ An extension of the present analysis to those servicemembers with one and more than two concussive events is warranted, in part to assess the public

\footnotetext{
*Zoroya G. Joint Chiefs Chairman seeks brain-injury limit [Internet]. McLean (VA): USA Today; 2009 [updated 2009 Sep 28; cited 2010 Jan 14]. Available from: http://www.usatoday.com/news/military/ 2009-09-27-brain-injury-limit N.htm.
} 
JRRD, Volume 48, Number 10, 2011

Table 6.

Age-adjusted associations from logistic regression modeling predictors of postinjury utilization of mental health and neurology outpatient services $(n=107){ }^{*}$

\begin{tabular}{|c|c|c|c|c|c|c|}
\hline \multirow{2}{*}{ Characteristic } & \multicolumn{3}{|c|}{ Mental Health } & \multicolumn{3}{|c|}{ Neurology } \\
\hline & OR & CI & $p$-Value & OR & CI & $p$-Value \\
\hline \multicolumn{7}{|l|}{$\overline{C o n c u s s i o n ~ S e v e r i t y ~}^{\dagger}$} \\
\hline \multicolumn{7}{|l|}{ First Event } \\
\hline Unadjusted & 0.87 & $0.26-2.92$ & 0.82 & 1.12 & $0.44-2.84$ & 0.81 \\
\hline Adjusted & 0.87 & $0.26-2.92$ & 0.82 & 1.12 & $0.44-2.85$ & 0.81 \\
\hline \multicolumn{7}{|l|}{ Second Event } \\
\hline Unadjusted & 3.94 & $7^{1.37-}$ & 0.01 & 3.03 & $1.22-7.47$ & 0.02 \\
\hline Adjusted & 4.74 & $1.52-$ & 0.01 & 3.41 & $1.32-8.75$ & 0.01 \\
\hline \multicolumn{7}{|l|}{$\begin{array}{l}\text { Time Between Events } \\
\leq \text { Median }\end{array}$} \\
\hline Unadjusted & 0.60 & $0.21-1.67$ & 0.33 & 0.67 & $0.30-1.51$ & 0.34 \\
\hline $\begin{array}{l}\text { Adjusted } \\
\leq 2 \text { Weeks }\end{array}$ & 0.59 & $0.21-1.67$ & 0.32 & 0.67 & $0.30-1.51$ & 0.33 \\
\hline Unadjusted & 1.30 & $0.38-4.49$ & 0.67 & 1.14 & $0.41-3.16$ & 0.81 \\
\hline $\begin{array}{l}\text { Adjusted } \\
\leq 3 \text { Months }\end{array}$ & 1.30 & $0.38-4.47$ & 0.68 & 1.13 & $0.41-3.15$ & 0.81 \\
\hline Unadjusted & 3.17 & $0.39-$ & 0.28 & 2.13 & $0.56-8.11$ & 0.27 \\
\hline Adjusted & 3.31 & $\begin{array}{l}0.40- \\
7\end{array}$ & 0.26 & 2.20 & $0.57-8.46$ & 0.25 \\
\hline
\end{tabular}

health implications of a concussion-limit policy and also to more clearly define the effects of two concussions, a topic on which civilian studies have yielded mixed findings $[14,24-26]$.

Little is known about the mediating effect of time between concussive events. The time interval between the first and second concussion in the present analysis did not statistically affect healthcare utilization following the second event. It should be noted, however, that those who experienced a repeat concussion less than 3 months after their initial concussion trended toward higher odds of utilizing mental health and neurology services, but the small sample size may have limited our ability to detect a statistical association. A recent study among professional football players found no association of time between repeat concussions and number of reported postconcussive symptoms [21]. Another study found similar results, though time between events was analyzed as a dichotomous variable of less than or greater than 6 months, which may have diluted any association [27]. One recent study found evidence of a mediating effect of time, but this study used electroencephalography to directly measure brain function [14]. The severity measure used in the present study (AIS) may not have been sensitive or specific enough to show an association, and healthcare utilization may be more a reflection of willingness to present for care. As indicated by the aforementioned research, a mediating effect of time may be better studied with neurological tests or rates of self-reported symptoms following the first and subsequent concussive events. More focused research may eventually lead to policies similar to the "return-to-play" guidelines implemented in high school and collegiate athletics [28].

The greatest strength of this study was the use of provider-diagnosed cases of concussion. Most similar studies rely on self-report information, which may be subject to recall bias. Additionally, the EMED data allowed for abstraction of injury dates, from which time between events was calculated. This capability is unique because accurate dates of injury for mild concussion may not be otherwise documented, particularly in such an austere environment. The ability to link EMED data with elec- 
tronic medical databases also allowed for the examination of long-term healthcare utilization.

The primary limitation of this study was the small sample size. It is possible that the lack of a larger sample precluded significant findings. In addition, only personnel who reported to and were treated at Navy-Marine Corps facilities were included in the present analysis. As such, Marines were likely overrepresented in the sample, and untreated injuries or injuries treated at other facilities, such as U.S. Army Combat Support Hospitals, were not represented. In addition, information regarding LOC was often not indicated; thus missing data precluded any detailed assessment of this variable. Information related to the underlying cause of blast-related concussion, whether due to blast overpressure or resulting blunt trauma, was not available for analysis at the time of this study and may have affected results. Given adequate sample size, future research should incorporate a thorough assessment of the physical cause of concussion. Finally, although the healthcare utilization data were contingent on remaining in military service, results did not change when excluding personnel who were discharged from the military during the 2-year follow-up period $(n=3)$.

\section{CONCLUSIONS}

This is the one of the first reports of repeated concussion among military personnel in a combat-deployed setting. Although the relationship of time between events and health outcomes remains unclear, further study on the cumulative effects of multiple concussive events among military personnel is warranted and may be strengthened by a larger sample size, in addition to cognitive and neurological testing. Military personnel are at risk for repeated concussion. Detailed postconcussion outcome analysis and assessment is essential in order to improve overall well-being, maximize force readiness, and refine clinical management and treatment protocols.

\section{ACKNOWLEDGMENTS}

\section{Author Contributions:}

Study concept and design: A. J. MacGregor, A. L. Dougherty, R. H. Morrison, K. H. Quinn, M. R. Galarneau.

Acquisition of data: A. J. MacGregor, R. H. Morrison, K. H. Quinn, M. R. Galarneau.
Analysis and interpretation of data: A. J. MacGregor, A. L. Dougherty, R. H. Morrison.

Drafting of manuscript: A. J. MacGregor, A. L. Dougherty,

R. H. Morrison.

Critical revision of manuscript for important intellectual content:

A. L. Dougherty, K. H. Quinn, M. R. Galarneau.

Final approval of published version: A. J. MacGregor,

A. L. Dougherty, R. H. Morrison, K. H. Quinn, M. R. Galarneau.

Financial Disclosures: The authors have declared that no competing interests exist.

Funding/Support: This material was based on work supported by the Congressionally Directed Medical Research Programs, Department of Defense (proposal PT090804 under work unit 61024).

Additional Contributions: The authors thank Science Applications International Corporation for its contribution to this work. They would especially like to thank data analysts Jay Walker and Kevin Heltemes for their assistance with this project. They would also like to thank Dr. Karl Van Orden for assistance with study design and Dr. Mary Clouser for assistance with manuscript review.

Institutional Review: This research was approved by the Institutional Review Board at NHRC. This research has been conducted in compliance with all applicable Federal regulations governing the protection of human subjects in research (protocol NHRC.2003.0025).

Participant Follow-Up: The authors do not plan to notify participants of the publication of this study because of a lack of contact information.

Disclaimer: The views and opinions expressed herein are those of the authors and do not necessarily reflect the official policy or position of the Department of the Navy, Department of Defense, or U.S.

Government.

\section{REFERENCES}

1. Okie S. Traumatic brain injury in the war zone. $\mathrm{N}$ Engl J Med. 2005;352(20):2043-47. [PMID: 15901856] http://dx.doi.org/10.1056/NEJMp058102

2. Warden D. Military TBI during the Iraq and Afghanistan wars. J Head Trauma Rehabil. 2006;21(5):398-402. [PMID: 16983225] http://dx.doi.org/10.1097/00001199-200609000-00004

3. Martin EM, Lu WC, Helmick K, French L, Warden DL. Traumatic brain injuries sustained in the Afghanistan and Iraq wars. Am J Nurs. 2008;108(4):40-47.

[PMID: 18367927] http://dx.doi.org/10.1097/01.NAJ.0000315260.92070.3f

4. Zeitzer MB, Brooks JM. In the line of fire: Traumatic brain injury among Iraq war veterans. AAOHN J. 2008;56(8): 347-53. [PMID: 18717301$]$ http://dx.doi.org/10.3928/08910162-20080801-03

5. Invisible wounds of war: Psychological and cognitive injuries, their consequences, and services to assist recovery [Internet]. Santa Monica (CA): RAND; 2008. Available from: http://www.rand.org/multi/military/veterans/ 
6. Hoge CW, McGurk D, Thomas JL, Cox AL, Engel CC, Castro CA. Mild traumatic brain injury in U.S. soldiers returning from Iraq. N Engl J Med. 2008;358(5):453-63. [PMID: 18234750]

http://dx.doi.org/10.1056/NEJMoa072972

7. MacGregor AJ, Shaffer RA, Dougherty AL, Galarneau MR, Raman R, Baker DG, Lindsay SP, Golomb BA, Corson KS. Prevalence and psychological correlates of traumatic brain injury in Operation Iraqi Freedom. J Head Trauma Rehabil. 2010;25(1):1-8. [PMID: 20051901] http://dx.doi.org/10.1097/HTR.0b013e3181c2993d

8. Gondusky JS, Reiter MP. Protecting military convoys in Iraq: An examination of battle injuries sustained by a mechanized battalion during Operation Iraqi Freedom II. Mil Med. 2005;170(6):546-49. [PMID: 16001610]

9. Guskiewicz KM, Marshall SW, Bailes J, McCrea M, Cantu RC, Randolph C, Jordan BD. Association between recurrent concussion and late-life cognitive impairment in retired professional football players. Neurosurgery. 2005; 57(4):719-26. [PMID: 16239884] http://dx.doi.org/10.1227/01.NEU.0000175725.75780.DD

10. Jordan BD. Chronic traumatic brain injury associated with boxing. Semin Neurol. 2000;20(2):179-85.

[PMID: 10946737]

http://dx.doi.org/10.1055/s-2000-9826

11. Thornton AE, Cox DN, Whitfield K, Fouladi RT. Cumulative concussion exposure in rugby players: Neurocognitive and symptomatic outcomes. J Clin Exp Neuropsychol. 2008; 30(4):398-409. [PMID: 18938678] http://dx.doi.org/10.1080/13803390701443662

12. Gronwall D, Wrightson P. Cumulative effect of concussion. Lancet. 1975;2(7943):995-97. [PMID: 53547] http://dx.doi.org/10.1016/S0140-6736(75)90288-3

13. Salcido R, Costich JF. Recurrent traumatic brain injury. Brain Inj. 1992;6(3):293-98. [PMID: 1581750] http://dx.doi.org/10.3109/02699059209029671

14. Slobounov S, Cao C, Sebastianelli W. Differential effect of first versus second concussive episodes on wavelet information quality of EEG. Clin Neurophysiol. 2009;120(5): 862-67. [PMID: 19375981] http://dx.doi.org/10.1016/j.clinph.2009.03.009

15. Collins MW, Grindel SH, Lovell MR, Dede DE, Moser DJ, Phalin BR, Nogle S, Wasik M, Cordry D, Daugherty KM, Sears SF, Nicolette G, Indelicato P, McKeag DB. Relationship between concussion and neuropsychological performance in college football players. JAMA. 1999;282(10): 964-70. [PMID: 10485682] http://dx.doi.org/10.1001/jama.282.10.964

16. Barth JT, Alves WM, Ryan TV, Macciocchi SN, Rimel RW, Jane JA, Nelson WE. Mild head injury in sports: Neuropsychological sequelae and recovery of function. In:
Levin HS, Eisenberg HM, Benton AL, editors. Mild head injury. New York (NY): Oxford University Press; 1989.

17. Galarneau MR, Hancock WC, Konoske P, Melcer T, Vickers RR, Walker GJ, Zouris JM. The Navy-Marine Corps Combat Trauma Registry. Mil Med. 2006;171(8):691-97. [PMID: 16933807]

18. Gennarelli TA, Wodzon E. Abbreviated Injury Scale 2005. Barrington (IL): Association for the Advancement of Automotive Medicine; 2005.

19. Baker SP, O’Neill B, Haddon W Jr, Long WB. The Injury Severity Score: A method for describing patients with multiple injuries and evaluating emergency care. J Trauma. 1974;14(3):187-96. [PMID: 4814394]

http://dx.doi.org/10.1097/00005373-197403000-00001

20. Commission on Professional Hospital Activities. International Classification of Diseases, 9th Revision, Clinical Modification. Ann Arbor (MI): Edwards Brothers; 1977.

21. Pellman EJ, Viano DC, Casson IR, Tucker AM, Waeckerle JF, Powell JW, Feuer H. Concussion in professional football: Repeat injuries_-Part 4. Neurosurgery. 2004;55(4): 860-76. [PMID: 154585941 http://dx.doi.org/10.1227/01.NEU.0000137657.00146.7D

22. McAllister TW. Mild brain injury and the postconcussion syndrome. In: Silver JM, McAllister TW, Yudofsky SC, editors. Textbook of traumatic brain injury. Washington (DC): American Psychiatric Publishing, Inc; 2005. p. 279-308.

23. Guskiewicz KM, McCrea M, Marshall SW, Cantu RC, Randolph C, Barr W, Onate JA, Kelly JP. Cumulative effects associated with recurrent concussion in collegiate football players: The NCAA Concussion Study. JAMA. 2003;290(19):2549-55. [PMID: 14625331]

http://dx.doi.org/10.1001/jama.290.19.2549

24. Guskiewicz KM, Marshall SW, Bailes J, McCrea M, Harding HP Jr, Matthews A, Mihalik JR, Cantu RC. Recurrent concussion and risk of depression in retired professional football players. Med Sci Sports Exerc. 2007;39(6):903-9. [PMID: 17545878] http://dx.doi.org/10.1249/mss.0b013e3180383da5

25. Macciocchi SN, Barth JT, Littlefield L, Cantu RC. Multiple concussions and neuropsychological functioning in collegiate football players. J Athl Train. 2001;36(3):303-6. [PMID: 12937500]

26. Iverson GL, Brooks BL, Lovell MR, Collins MW. No cumulative effects for one or two previous concussions. $\mathrm{Br}$ J Sports Med. 2006;40(1):72-75. [PMID: 16371496] http://dx.doi.org/10.1136/bjsm.2005.020651

27. Teasdale TW, Engberg AW. Cognitive dysfunction in young men following head injury in childhood and adolescence: A population study. J Neurol Neurosurg Psychiatry. 2003;74(7):933-36. [PMID: 12810783] http://dx.doi.org/10.1136/jnnp.74.7.933 
28. McCrory P, Meeuwisse W, Johnston K, Dvorak J, Aubry M, Molloy M, Cantu R. Consensus statement on concussion in sport-The Third International Conference on Concussion in Sport held in Zurich, November 2008. Phys Sportsmed. 2009;37(2):141-59. [PMID: 20048521] http://dx.doi.org/10.3810/psm.2009.06.1721

Submitted for publication January 29, 2011. Accepted in revised form August 9, 2011.
This article and any supplementary material should be cited as follows:

MacGregor AJ, Dougherty AL, Morrison RH, Quinn KH, Galarneau MR. Repeated concussion among U.S. military personnel during Operation Iraqi Freedom. J Rehabil Res Dev. 2011;48(10):1269-78.

DOI:10.1682/JRRD.2011.01.0013

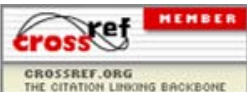


